Niels Grabow*, Volkmar Senz, Klaus-Peter Schmitz

\title{
Transfer activities for cardiovascular, ophthalmologic and otolaryngologic medical device innovations
}

\author{
Progress report 2020 from the Twenty20 consortium RESPONSE
}

\begin{abstract}
The consortium RESPONSE is a cooperation of partners from science and industry within the BMBFProgram "Twenty20 - Partnership for Innovation", 20142021. Current efforts are being made towards the transfer of new products, technologies and processes in the field of medical devices. Here, RESPONSE is focusing on novel concepts of implantable medical devices for cardiovascular, ophthalmologic and otolaryngologic application. Platform technology approaches, such as drug delivery systems for responsive functionalized implants or smart implant technologies, are being used to enable new applications.
\end{abstract}

See also: www.response.uni-rostock.de

Keywords: implant, combination product, stent, heart valve, glaucoma, Eustachian tube, cochlea, Fallopian tube, pancreas

https://doi.org/10.1515/cdbme-2020-3022

\section{Mission}

Since the German Federal Ministry's for Education and Research (BMBF) publishing of the funding guidelines "Twenty20 - Partnership for Innovation" in August 2012, the research consortium "RESPONSE - Partnership for Innovation in Implant Technology" has actively been pursuing the identification, implementation and transfer of significant technology-driven medical device innovations.

In its endeavors to improve patient-centered care towards

\footnotetext{
*Corresponding author: Niels Grabow: Institute for Biomedical Engineering, University Medical Center Rostock, FriedrichBarnewitz-Str. 4, 18119 Rostock, e-mail: niels.grabow@unirostock.de

Volkmar Senz: Institute for Biomedical Engineering, University Medical Center Rostock, Germany

Klaus-Peter Schmitz: Institute for Biomedical Engineering, University Medical Center Rostock, and Institute for ImplantTechnology and Biomaterials e.V., Warnemuende, Germany
}

increased health and quality of life, the consortium is focusing on widespread diseases with the potential for their alleviation through optimized implantable medical devices.

Emanating from the so-called "initial concept", RESPONSE has continuously advanced the definition of its scientific, economic and social objectives, as well as its pathway to accomplishment via contributions to innovation in implant technology.

\section{Creation of value}

In accordance with $\mathrm{BMBF}$ funding targets, the creation of value through participating industry partners is ascribed particular importance within the "Twenty20" program.

Based on its portfolio of partners, RESPONSE is centered on pre-competitive $\mathrm{R} \& \mathrm{D}$ activities in cardiovascular medicine, ophthalmology and otolaryngology. Also, quite recently projects have been started towards gynecologic (Fallopian tube) and gastroenterologic (pancreas) implant applications.

Internationally, this sphere of activity is driven by high clinical demands and tremendous potential for industrial exploitation. Against this background, RESPONSE has initiated a so-called "transfer phase", starting in 2020, which is dedicated to the conversion of scientific results into industrial and clinical translation.

In preparation of the transfer activities, RESPONSE has analyzed its progress in the context of the prospective scientific and economic potential. During this process, which was guided by the managing and advisory boards, innovations for new products, technologies and processes have been identified for transfer.

\section{Innovations}

In the field of cardiovascular implants, RESPONSE is aiming at covered stent and scaffold systems as bail-out devices for 
endovascular sealing [1], as well as at novel electrospun nonwoven materials for minimally invasive percutaneous transcatheter heart valve prostheses [2].

A clinical translation of ophthalmic implants for glaucoma treatment is aspired [3], as well as of otolaryngologic stents for the treatment of Eustachian tube dysfunction [4].

Within the newly accrued branch of gynecology, Fallopian tube stenting for the treatment of proximal tube stenosis shall be advanced towards ongoing scientific connectivity of the development concept.

Throughout these fields, the RESPONSE partners are highly ambitious in contributing solutions for the international medical device markets.

Internationally perceived are RESPONSE's technological innovations, which are being sought for biomaterials and drug delivery regarding the development of responsive functionalized implants [5].

In silico methods for the simulation of fluid dynamics and structural mechanics shall enable the design process of implants with novel characteristics [6]. Here, the complex simulation of fluid-structure interaction is of particular importance for the reduction of the thrombotic potential of artificial venous valve and heart valve structures.

Following a recommendation of the RESPONSE advisory board, the consortium is making efforts to access the opportunities of the so-called "smart implants" concept for novel diagnostic and therapeutic implant functions. Here, the emphasis is on cardiovascular applications. While the term "smart implant" or "intelligent implant" conventionally applies to implants with measuring or control functions, it is also being extended towards innovative biomechanical, biological or materials approaches for active implants.

An integrative aim of the consortium is the enhancement of innovation processes for participative technology development, integrating the perspectives of developers, medical professionals from different supply areas, as well as systems and innovation researchers. Here, the individual and social benefit, the gain in quality of life, and the related costs are being quantified. Demographic research, based on patient-related data, is used as a starting point for the differential assessment of alternative therapeutic concepts [7]. Influencing factors of the relevant German and international health markets, with their respective regulatory and reimbursement mechanisms, are being studied together with industry. Ultimately, this will yield systematic considerations for the evaluation of implant innovations, as well as demand analyses, and the examination of costeffectiveness ratios.
Another important aspect of transfer is the development of standardized test protocols along the entire translation chain - from the first prototype tests to the final approval tests. Here, the integration of sensor and actuator systems in combination with physical and chemical analytics will establish the basis for adequate measuring and test procedures for medical devices in light of the increasing regulatory requirements [8].

This planned portfolio of RESPONSE key innovations takes into consideration the opportunities for transfer of new medical devices, technologies and processes, beyond the completion of the funding period in 2021 .

\section{Author Statement}

Research funding: Financial support by the German Federal Ministry of Education and Research (BMBF program: Twenty20 - Partnership for Innovation) for the project "RESPONSE - Partnership for Innovation in Implant Technology" is gratefully acknowledged. Conflict of interest: Authors state no conflict of interest.

\section{References}

[1] Patents pending.

[2] Illner S, Arbeiter D, Teske M, Khaimov V, Oschatz ST, Senz V, Schmitz KP, Grabow N, Kohse S. Tissue biomimicry using cross-linked electrospun nonwoven fiber composites. Curr Dir Biomed Eng, 2019;5(1):119-122.

[3] Siewert S, Reske T, Pfensig S, Großmann S, Schmidt W, Stahnke T, Guthoff R, Grabow N, Stiehm M, Schmitz K-P. Development of an antifibrotic drug-eluting coating for a minimally invasive implantable glaucoma microstent. Curr Dir Biomed Eng, 2019;5(1):215-218.

[4] Schubert J, Wilfling T, Paasche G, Lenarz T, Schümann K, Grabow N, Schmidt W, Schmitz KP. Investigation of balloon dilation devices for treatment of Eustachian tube dysfunction. Curr Dir Biomed Eng, 2018;4(1):529-533.

[5] Maitz MF, Martins MCL, Grabow N, Matschegewski C, Huang N, Chaikof EL, Barbosa MA, Werner C, Sperling C. The blood compatibility challenge Part 4: Surface modification for hemocompatible materials: passive and active approaches to guide blood-material interactions. Acta Biomater. 2019;pii:S1742-7061(19)30430-1.

[6] Stiehm M, Borowski F, Kaule S, Ott R, Pfensig S, Siewert S, Grabow N, Schmitz KP. Computational and experimental flow analysis of the thrombotic potential of transcatheter aortic valve prostheses according to ISO 5840. Curr Dir Biomed Eng, 2019;5(1):123-126.

[7] Kreft D, Keiler J, Grambow E, Kischkel S, Wree A, Doblhammer G. Prevalence and Mortality of Venous Leg Diseases of the Deep Veins: An Observational Cohort Study Based on German Health Claims Data. Angiology. 2020;3319720905751.

[8] Klar E. Medical Device Regulation as current challenge for the legally safe introduction of new technologies. Chirurg. 2018;89(10):755-759 